\title{
Efeito do Genótipo sobre a Produção e a Composição do Leite de Cabras Mestiças
}

\author{
Nelson Nogueira Barros ${ }^{1}$, Francisco Luiz Ribeiro da Silva ${ }^{1}$, Marcos Cláudio Pinheiro Rogério²
}

\begin{abstract}
RESUMO - O potencial de produção de trinta e cinco cabras mestiças - 12 1/2Pardo-alpina + 1/2Moxotó (1/2PA-M), 113/4 Pardoalpina + 1/4Moxotó (3/4PA-M) e 12 Tricross (1/2Anglo-nubiana + 1/4Pardo-alpina + 1/4Moxotó) - foi avaliado em um experimento foi conduzido na Embrapa Caprinos. Os cabritos foram separados das respectivas mães ao nascimento. As cabras foram ordenhadas duas vezes ao dia e o controle leiteiro procedido semanalmente. Os animais foram confinados em baias coletivas e receberam dieta para produção de $2,5 \mathrm{~kg}$ de leite/dia, composta de silagem de sorgo ad libitum e concentrado. Os animais foram pesados em intervalos de 14 dias. A produção de leite, como coletada, não foi influenciada pelo genótipo. No entanto, quando foi corrigida para $4 \%$ de gordura, o genótipo $1 / 2$ PA-M foi superior aos 3/4 PA-M e Tricross. Não houve diferença significativa entre genótipos para gordura, proteína e extrato seco total do leite.
\end{abstract}

Palavras-chave: caprino leiteiro, grupos genéticos, peso corporal

\section{Effect of Genotype on Milk Yield and Composition of Crossbred Goats}

\begin{abstract}
The objective of this trial was to study the production of thirty-five crossbred goats: ${ }^{1 / 2}$ Brown Alpine $\mathrm{x} 12^{1 /}$ ${ }^{2}$ Moxoto $\left({ }^{1 / 2} \mathrm{BA}-\mathrm{M}\right), 11{ }^{3 / 4}$ Brown Alpine $\mathrm{x}{ }^{1 / 4}$ Moxoto $\left({ }^{3 / 4} \mathrm{BA}-\mathrm{M}\right)$, and 12 Tricross $\left({ }^{1 / 2}\right.$ Anglo Nubian $\mathrm{x}{ }^{1 / 4}$ Moxoto $\mathrm{x}{ }^{1 / 4}$ Brown Alpine). After birth, the kids were separated from their mothers. Goats were milked twice a day and milk composition determined weekly. Animals were housed in collective pens and received a diet composed of sorghum silage (ad libitum) plus concentrate that were formulated to allow $2.5 \mathrm{~kg} / \mathrm{d}$ of milk yield. Animals were weighted every 14 days. Milk production did not differ among genotypes. However, $4 \%$ fat corrected milk was greater for ${ }^{1 / 2} \mathrm{BA}-\mathrm{M}$ than the remaining groups. No significant differences were observed for milk composition (fat, protein, and total solids) across genotypes in the current trial.
\end{abstract}

Key Words: body weight, dairy goat, genetic groups

\section{Introdução}

A produção de leite é resultante do genótipo do animal e do ambiente em que vive (Falconer \& Mackay, 1996). A alimentação é um dos principais componentes ambientais e constitui-se em importante fator restritivo à produção de leite caprino no semi-árido brasileiro. Nessa região, tradicionalmente, a oferta de forragens provém da caatinga, que sofre grande influência das estações chuvosa e seca. Durante a estação chuvosa, o alimento disponível na caatinga é abundante e de boa qualidade nutritiva, ao passo que, na seca, tanto a disponibilidade como a qualidade da forragem sofrem perdas acentuadas, em virtude do aumento da fração fibrosa, do incremento da lignificação da parede celular e da redução nos teores de proteína bruta das gramíneas (Pfister, 1983; Kirmse, 1985).

As raças de caprinos nativos do Nordeste brasileiro (Moxotó e Canindé) e outros tipos raciais, como Marota e Repartida, são importantes para o semi-árido, graças à elevada rusticidade, porém apresentam limitações quanto à produção de leite (Silva \& Mello, 1997). Os cruzamentos dessas raças com raças exóticas especializadas para produção de leite aliam rusticidade e produtividade, fatores importantes para os sistemas de produção nos semiáridos. Assim, Barbieri et al. (1989) observaram produções de leite de $0,93 \mathrm{~kg} /$ dia, em lactação de 158 dias e de $0,91 \mathrm{~kg} /$ dia em lactação de 157 dias, para os grupos genéticos 1/2 PA - SRD e 3/4 PA - SRD, respectivamente.

Analisando lactações de 168 dias, Cancio et al. (1993) registraram produções de 0,39 e 1,2 kg/dia, em relação ao tipo racial Marota e o genótipo 1/2 Marota Saanen, respectivamente.

Este trabalho foi conduzido com o objetivo de determinar o potencial de produção leiteira e a composição do leite de cabras $1 / 2$ Pardo-Alpina + 1/2Moxotó, $3 / 4$ Pardo-alpina + 1/4Moxotó e Tricross (1/2Anglonubiana $+1 / 4$ Pardo-alpina $+1 / 4$ Moxotó). 


\section{Material e Métodos}

O experimento foi conduzido na Embrapa Caprinos, em Sobral-CE, no período de 19 de agosto de 1998 a 20 de janeiro de 1999, com início no sétimo dia após a parição das cabras. Foram utilizadas 35 cabras $\mathrm{F}_{1}$ entre a segunda e a quarta ordem de parto (12 $1 / 2$ Pardo-alpina $+1 / 2$ Moxotó ( $1 / 2 \mathrm{PA}-\mathrm{M})$, onze $3 / 4$ Pardoalpina $+1 / 4$ Moxotó ( $3 / 4$ PA-M) e 12 Tricross ( $1 / 2$ Anglonubiana $+1 / 4$ Pardo-alpina $+1 / 4$ Moxotó). Os grupos foram balanceados para ordem de parto. Os cabritos foram separados das respectivas mães ao nascimento, como medida de controle da Artrite Encefalite Caprina a Vírus (CAEV). Em seguida, as cabras foram distribuídas nos respectivos grupos, realizando-se o primeiro controle leiteiro após 14 dias de lactação e a pesagem dos animais, em intervalos de 14 dias.

Os animais foram confinados em baias coletivas, por grupo genético, onde receberam silagem de sorgo ad libitum e concentrado limitado a $800 \mathrm{~g} / \mathrm{animal} / \mathrm{dia}$ até a décima sexta semana de experimento. Daí em diante, foram ofertados $700 \mathrm{~g}$ de concentrado/animal/ dia (metade pela manhã e metade pela tarde). A dieta foi formulada segundo o NRC (1981), para atender à produção leiteira de $2,5 \mathrm{~kg} / \mathrm{animal} / \mathrm{dia}$. Diariamente, foram retiradas amostras do alimento oferecido, obtendo-se, ao final de cada semana, uma amostra composta, que foi posteriormente analisada (Tabela 1).

A ordenha foi realizada duas vezes ao dia e o controle leiteiro foi feito em intervalos de sete dias. A cada 14 dias, foram coletadas amostras de leite, individualmente, de seis cabras por grupo genético, para se evitar sobrecarga do laboratório. As amostras da manhã e da tarde foram misturadas, homogeneizadas, analisando-se os teores de extrato seco total, gordura e proteína bruta. Na avaliação da produção de leite $(\mathrm{kg} /$ cabeça/dia), utilizaram-se as variáveis leite como coletado e leite corrigido para $4 \%$ de gordura, conforme metodologia descrita pela EMBRATER (1984). As cabras foram pesadas ao parto e, em seguida, em intervalos de14 dias até o final do experimento.

A análise de variância foi realizada adotando-se o procedimento GLM do programa SAS (1990). O peso da mãe ao parto, como covariável, não foi significativo e, portanto, foi desconsiderado. O modelo estatístico empregado foi:
Tabela 1 - Composição dos alimentos oferecidos às cabras Table 1 - Chemical composition of ingredients

\begin{tabular}{|c|c|c|}
\hline $\begin{array}{l}\text { Composição (\%) } \\
\text { Composition (\%) }\end{array}$ & $\begin{array}{l}\text { oncentrado }^{1} \\
\text { Concentrate }^{1}\end{array}$ & $\begin{array}{c}\text { Volumoso }^{2} \\
\text { Forage }^{2}\end{array}$ \\
\hline Milho em grão & \multirow[t]{2}{*}{56,60} & \multirow[t]{2}{*}{-} \\
\hline Corn grain & & \\
\hline Farelo de soja & \multirow[t]{2}{*}{40,00} & \multirow[t]{2}{*}{-} \\
\hline Soy bean meal & & \\
\hline Fosfato bicálcico & \multirow[t]{2}{*}{2,80} & \multirow[t]{2}{*}{-} \\
\hline Dicalcium phosphate & & \\
\hline Sal comum $(\mathrm{NaCl})$ & \multirow[t]{2}{*}{0,60} & \multirow[t]{2}{*}{ - } \\
\hline Salt $(\mathrm{NaCl})$ & & \\
\hline Total & \multirow{2}{*}{$\begin{array}{r}100,00 \\
88,90\end{array}$} & \multirow{2}{*}{34,70} \\
\hline Matéria seca (\%) & & \\
\hline \multicolumn{3}{|c|}{$\begin{array}{l}100 \% \text { da matéria seca } \\
100 \% \text { of the dry matter }\end{array}$} \\
\hline Proteína bruta (\%) & \multirow[t]{2}{*}{24,0} & \multirow[t]{2}{*}{4,47} \\
\hline Crude protein (\%) & & \\
\hline Fibra em detergente neutro $(\%)$ & \multirow[t]{2}{*}{14,19} & \multirow[t]{2}{*}{62,24} \\
\hline Neutral detergent fiber (\%) & & \\
\hline Hemicelulose $(\%)$ & \multirow[t]{2}{*}{8,14} & \multirow[t]{2}{*}{25,56} \\
\hline Hemicellulose (\%) & & \\
\hline Celulose $(\%)$ & \multirow[t]{2}{*}{4,09} & \multirow[t]{2}{*}{33,62} \\
\hline Cellulose (\%) & & \\
\hline Lignina $(\%)$ & \multirow[t]{2}{*}{1,96} & \multirow[t]{2}{*}{4,37} \\
\hline Lignin $(\%)$ & & \\
\hline
\end{tabular}

$1800 \mathrm{~g} / \mathrm{animal} / \mathrm{dia}$ até a $16^{\mathrm{a}}$ semana e, posteriormente, $700 \mathrm{~g} / \mathrm{animal} / \mathrm{dia}$ (800 g/animal/day up to $16^{\text {th }}$ week and, $700 \mathrm{~g} / \mathrm{animal} /$ day thereafter).

2 Silagem de sorgo ad libitum (Ad libitum sorghum silage).

$$
Y_{i j}=m+G_{i}+E_{e i j}
$$

em que: $\mathrm{m}=$ constante inerente às observações; $\mathrm{G}_{\mathrm{i}}=$ efeito dos grupos genéticos; $\mathrm{E}_{\text {eij }}$ = erro aleatório, associado a cada observação.

Depois de aplicado o teste F, o comportamento dos diferentes genótipos foi avaliado pelo teste LSD, a $5 \%$ de probabilidade.

\section{Resultados e Discussão}

Os valores referentes à produção de leite das cabras encontram-se na Tabela 2 e na Figura 1.

A produção de leite, como coletada, não diferiu $(\mathrm{P}>0,05)$ entre os grupos genéticos (Tabela 2). No entanto, quando corrigida para teor de gordura do leite, o grupo genético $1 / 2$ PA-M foi superior $(\mathrm{P}<0,05)$ aos demais $(3 / 4$ PA-M e (Tricross). 
Tabela 2 - Médias estimadas pelos quadrados mínimos e respectivos erros-padrão, referentes às produções de leite de cabras $1 / 2$ Pardo-alpina + $1 / 2$ Moxotó (1/2PA-M), 3/4Pardo-alpina + 1/4Moxotó $(3 / 4$ PA-M) e $1 / 2$ Anglo-nubiana + $1 / 4$ Pardo-alpina + $1 / 4$ Moxotó (Tricross)

Table 2 - Least square means and the respective standard errors for milk production of $1 / 2$ Brown Alpine $1 / 2$ (1/2 BA-M) Moxotó, $3 / 4$ Brown Alpine + 1/4 Moxotó (3/4BA-M) and $1 / 2$ Anglo Nubian $+1 / 4$ Brown Alpin + $1 / 4$ Moxotó (Tricross) goats

Grupo genético Produção de leite $(\mathrm{kg} / \mathrm{dia})^{1}$

Genetic group Milk composition $(\mathrm{kg} / \text { day })^{1}$

\begin{tabular}{lcc}
\cline { 2 - 2 } & $\begin{array}{c}\text { Como coletada } \\
\text { As collected }\end{array}$ & $\begin{array}{c}\text { Corrigida para } \\
4 \% \text { de gordura } \\
\text { Corrected for } \\
4 \% \text { of fat }\end{array}$ \\
\hline $1 / 2$ PA-M & $1,54 \pm 0,07^{\mathrm{a}}$ & $1,39 \pm 0,06^{\mathrm{a}}$ \\
$3 / 4$ PA-M & $1,33 \pm 0,07^{\mathrm{a}}$ & $1,14 \pm 0,06^{\mathrm{b}}$ \\
Tricross & $1,36 \pm 0,07^{\mathrm{a}}$ & $1,22 \pm 0,06^{\mathrm{b}}$ \\
Threecross & &
\end{tabular}

${ }^{1}$ Médias, na mesma coluna, seguidas de letras diferentes são estatisticamente distintas $(P<0,05)$ pelo teste LSD. Período de lactação de 154 dias.

${ }^{1}$ Means in a column, followed by different letter are different $(P<0.05)$ by LSD test. Lactation period of 154 days.

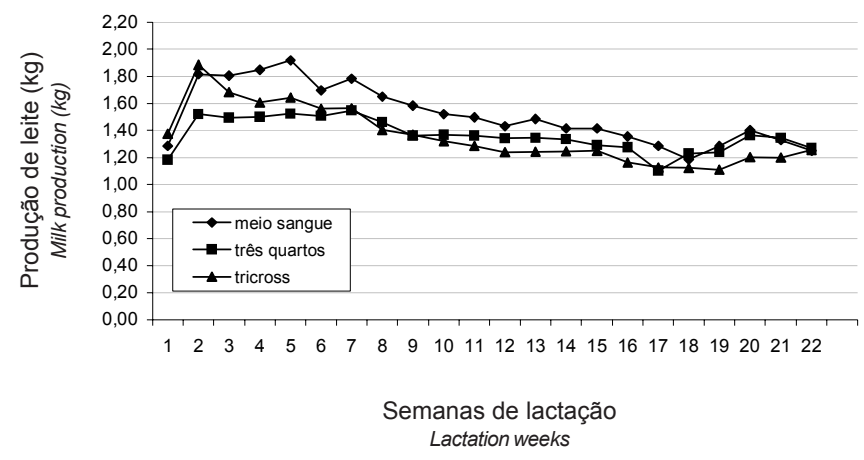

Figura 1 - Produção de leite (kg/dia) de cabras 1/2PardoAlpina + Moxotó (1/2PA-M), 3/4Pardo-Alpina + Moxotó (3/4PA-M) e $1 / 2$ Anglo-nubiana + 1/4PardoAlpina $+1 / 4$ Moxotó (Tricross)

Figure 1 - Milk production (kg/day) from $1 / 2$ Brown Alpine $+1 / 2$ Moxotó (BA-M), 3/4 Brown Alpine + 1/4Moxotó (BA-M) and $1 / 2$ Anglo Nubian $+1 / 4$ Brown Alpine $+1 / 4$ Moxotó (Tricross) goats.

A correção do leite para gordura provocou maior homogeneidade dentro de tratamento, refletida pelo menor erro-padrão (Tabela 2). $\mathrm{O}$ teor de gordura do leite do $1 / 2 \mathrm{PA}-\mathrm{M}$ foi de 3 e $2 \%$ superior ao do $3 / 4 \mathrm{PA}-\mathrm{M}$ e "Tricross" $(p<0,05)$, respectivamente. A superioridade do grupo genético $1 \frac{1}{2} \mathrm{PA}-\mathrm{M}$ pode ser atribuída, em parte, ao máximo vigor híbrido, que segundo Sheridan (1981), é mais expressivo na primeira gera- ção. No entanto, esperava-se que os grupos genéticos e $3 / 4$ PA-M fossem superiores ao $1 / 2$ PA-M, em virtude da maior participação de genes exóticos em suas composições genéticas.

Os dados existentes na literatura acerca destes grupos genéticos são escassos e relacionados a animais em pastejo na caatinga, razão pela qual são inferiores aos relatados neste trabalho. Assim, Barbieri et al. (1989) observaram produções de leite de $0,93 \mathrm{~kg} / \mathrm{dia}$, em lactação de 158 dias, e $0,91 \mathrm{~kg} /$ dia, em lactação de 157 dias, para os grupos genéticos $1 / 2 \mathrm{PA}-\mathrm{M}$ e $3 / 4 \mathrm{PA}-\mathrm{M}$, respectivamente. Ainda, Barbieri et al. (1990) relataram produções de leite 0,$570 ; 0,710 ;$ e $0,761 \mathrm{~kg} / \mathrm{dia}$ em lactação de 166, 205 e 201 dias, para o grupo genético 1/2PA-M, nos anos de 1986, 1987 e 1989, respectivamente. Pinto (1993), trabalhando com cabras $1 / 2 \mathrm{PA}$ $\mathrm{M}$, em pastejo na caatinga suplementadas com banco de proteína ou feno de cunhã (Clitoria ternatea), observaram produção média de leite, nos anos de 1990 e 1991, de 0,531 kg/dia em lactação de 132 dias. Melo Lima (1994) analisou 501 lactações de cabras $1 / 2$ PA-M, em pastejo na caatinga e suplementadas durante a época seca e observou produção média de $0,669 \mathrm{~kg}$ de leite/dia em lactações médias de 236 dias.

A produção de leite do grupo genético $1 / 2 \mathrm{PA}-\mathrm{M}$ (Tabela 2) observada neste trabalho foi muito superior às obtidas por Barbieri et al. (1989, 1990), Pinto (1993) e Melo Lima (1994) para animais do mesmo grupo genético em pastejo na caatinga e suplementado durante a estação seca, no semi-árido, indicando que as produções de leite observadas por estes autores, provavelmente, foram limitadas pela nutrição. Por outro lado, as produções obtidas neste trabalho correspondem ao potencial máximo de produção destes genótipos, uma vez que a dieta dos animais foi formulada para produção de $2,5 \mathrm{~kg}$ de leite/dia. Verifica-se na Figura 2 que os animais não perderam peso, nem mesmo no início da lactação, o que significa que a alimentação não foi fator limitante, reforçando a hipótese de que a produção de leite observada expressa o potencial de produção destes animais.

Na Tabela 3, estão apresentados os valores médios referentes à composição do leite (extrato seco total, gordura e proteína bruta).

Não foi detectada diferença significativa $(\mathrm{P}>0,05)$ entre grupos genéticos para as variáveis de qualidade do leite estudadas. Os resultados obtidos neste estudo contrariam os observados por Laguna et al., (1998) para estes mesmos grupos genéticos em pastejo na 
Tabela 3 - Médias estimadas pelos quadrados mínimos e respectivos erros-padrão, referentes à composição do leite de cabras $1 / 2$ Pardo-alpina + $1 / 2$ Moxotó ( $1 / 2 \mathrm{PA}-\mathrm{M}), 3 / 4$ Pardo-alpina + $1 / 2$ Moxotó ( $3 / 4$ PA-M) e $1 / 2$ Anglo-nubiana + 1/4Pardo-alpina + $1 / 4$ Moxotó (Tricross)

Table 3 - Least square means and the respectively standard errors for milk composition of $1 / 2$ Brown Alpine $+1 / 2$ Moxotó (1/2BA-m), 3/4 Brown Alpine + 1/4Moxotó (3/4 BA-M) and $1 / 2$ Anglo Nubian $+1 / 4$ Brown Alpine $+1 / 4$ Moxotó (Tricross) goats

\begin{tabular}{lccc}
\hline $\begin{array}{l}\text { Grupo genético } \\
\text { Genetic group }\end{array}$ & $\begin{array}{c}\text { Proteína } \\
\text { bruta } \\
\text { Crude protein } \\
(\%)\end{array}$ & $\begin{array}{c}\text { Gordura } \\
\text { Fat } \\
(\%)\end{array}$ & $\begin{array}{c}\text { Extrato } \\
\text { seco total } \\
\text { Total Solids } \\
(\%)\end{array}$ \\
\hline $1 / 2$ PA-M & $3,54 \pm 0,09$ & $3,33 \pm 0,04$ & $12,68 \pm 0,05$ \\
$3 / 4$ PA-M & $3,28 \pm 0,10$ & $3,11 \pm 0,04$ & $12,13 \pm 0,05$ \\
Tricross & $3,22 \pm 0,14$ & $3,28 \pm 0,06$ & $12,21 \pm 0,08$
\end{tabular}

Thricross

1 Não-significativo $(P>0,05)$

1 Not significant $(P>0.05)$.

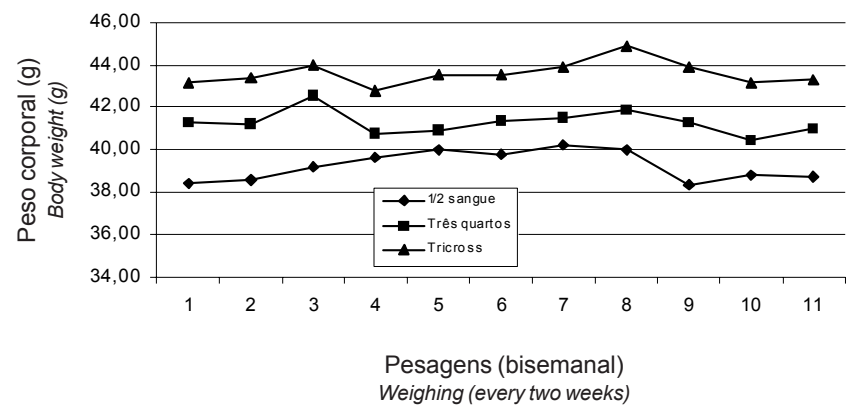

Figura 2 - Peso corporal de cabras 1/2Pardo-alpina + 1/2Moxotó (1/2 PA-M), 3/4Pardo-Alpina + 1/2Moxotó ( $3 / 4$ PA-M) e $1 / 2$ Anglo-nubiana + $1 / 4$ Pardo-Alpina $+1 / 4$ Moxotó

Figure 2 - Goat body weight $(\mathrm{kg})$ from $1 / 2$ Brown Alpine $+1 / 2$ Moxotó (BA-M), 3/4 Brown Alpine + 1/4Moxotó (3/4BA-M) and $1 / 2$ Anglo Nubian $+1 / 4$ Brown Alpine $+1 / 4$ Moxotó (Tricross) goats.

caatinga e suplementados com silagem de milho e concentrado durante a época seca; ou seja, estes autores verificaram que, no genótipo Tricross, os teores de gordura e de extrato seco total do leite, estimados em 5,23 e 14,24\%, foram superiores $(\mathrm{P}<0,05)$ aos 4,69 e $13,64 \%$ observados para o $1 / 2 \mathrm{PA}-$ $\mathrm{M}$, e estes, por sua vez, foram mais elevados que 4,32 e $13,11 \%$, respectivamente, encontrados para o $3 / 4 \mathrm{PA}-$ M. Todavia, neste experimento, a dieta dos animais continha mais concentrado que aquela utilizada no trabalho de Laguna et al. (1998), em que os animais foram mantidos exclusivamente a pasto durante a época chuvosa e, durante a época seca, receberam suplementação de volumoso e pequena quantidade de concentrado. Ciciliano-Jones \& Murphy (1989) relataram que o aumento de concentrado na dieta dos animais proporciona elevação das concentrações de ácido propiônico e redução na percentagem de ácido acético no rúmen. Palmquist \& Mattos (1978) esclareceram que a gordura do leite é sintetizada, principalmente, a partir do ácido acético. Provavelmente, o elevado nível de concentrado utilizado neste experimento em relação ao utilizado no trabalho de Laguna et al. (1998), explica em parte estas diferenças.

\section{Conclusões}

Cabras do grupo genético $1 / 2$ Pardo-alpina + $1 / 2$ Moxotó apresentaram maior potencial de produção de leite que os 3/4Pardo-alpina $+1 / 2$ Moxotó e Tricross (1/4Moxotó $+1 / 4$ Pardo-alpina $+1 / 2$ Anglo-nubiana) quando a produção de leite foi corrigida para $4 \%$ de gordura.

A composição do leite de cabras não variou entre os grupos genéticos estudados.

\section{Literatura Citada}

BARBIERI, M.E.; TOME, A.R.; SIMPLICIO, A.A.; ALVES, J.U. Avaliação da produção de leite de cabras mestiças 1/2 e 3/4 de sangue Parda Alemã com o tipo Sem Raça Definida. In: REUNIÃO ANUAL DA SOCIEDADE BRASILEIRA DE ZOOTECNIA, 25., 1989, Porto Alegre. Anais... Porto Alegre: Sociedade Brasileira de Zootecnia, 1989. p.431.

BARBIERI, M.E.; FIGUEIREDO, E.A.P.; SIMPLICIO, A.A. Produção de leite em cabras meio sangue Parda Alpina-Moxotó, em Sobral, Ceará. In: REUNIÃO ANUAL DA SOCIEDADE BRASILEIRA DE ZOOTECNIA, 27., 1990, Campinas. Anais... Piracicaba: Escola Superior de Estudos Agrários Luiz de Queiroz, 1990. p.408.

CANCIO, C.R.D.; CASTRO, R.S.; COELHO, L.D.A. et al. Idade ao primeiro parto, intervalo entre partos e produção leiteira de cabras Saanen, Marota e mestiças em Alagoas. Pesquisa Agropecuária Brasileira, v.27, n.1, p.53-59, 1993.

CICILIANO-JONES, C.J.; MURPHY, M.R. Production of volaty fat acids in the rumen and cecum-colon of steers as affected by forage:concentrate and forage physical form. Journal of Dairy Science, v.72, n.2, p.485-492, 1989.

EMBRATER. Criação de cabras leiteiras. Brasília: 1984. p.135136.

FALCONER, D.S.; MACKAY, T.F.C. Introduction to quantitative genetics. 4.ed. Harlow: Longman, 1996. 464p.

KIRMSE, R.D. Effect of clearing on forage production quality and decomposition in the caatinga woodland of Northeast Brazil. Logan: Utah State University, 1985. 150p. Dissertation (Doctor of Philosophy in Range Science) Uta State Unuversity, 1985. 
LAGUNA, L.E.; EGITO, A.S.; NUNES, R.G.F. Avaliação físicoquímica do leite de cabra de três rebanhos mestiços na região de Sobral, Ceará, Brasil. Revista do Instituto de Laticínios “Cândido Tostes", v.53, n.304, p.153-157,1998.

NATIONAL RESEARCH COUNCIL - NRC. Committee on Animal Nutrition. Subcommittee on Goat Nutrition (Washington, USA). Nutrient requirement on goat; Angora Dairy and meet goats in temperate and tropical countries. Washington, D.C.: National Academy Sciences, 1981. 91p.

PALMQUIST, D.L.; MATTOS, W. Turnover of lipoproteins and transfer to milk fat dietary (1-carbon-14) linoleic acid in lacting cows. Journal of Dairy Science, v.16, n.5, p.561$565,1978$.

PFISTER, J.A. Nutrition and feeding behavior of goat sheep grazing deciduos shrubs-woodland in Northeast Brazil. Logan: Utah State University, 1983. 130p. Dissertation (Doctor of Philosophy in Range Science) - Utah State Unuversity, 1983
STATISTICAL ANALYSES SYSTEM - SAS. SAS/STAT user's guide. Version 6. 4.ed., Cary: 1990. v.1, 943p.

SILVA, F.R.L.; MELLO, A.S. Produção de leite e prolificidade em cabras mestiças no Semi-Árido. In: REUNIÃO ANUAL DA SOCIEDADE BRASILEIRA DE ZOOTECNIA, 33. 1996, Fortaleza. Anais... Fortaleza: Sociedade Brasileira de Zootecnia, 1996. v.1, p.269-271.

Recebido em: 05/08/04

Aceito em: 09/03/05 